\title{
BMJ Open Physical activity and health-related quality of life in former elite and recreational cricketers from the UK with upper extremity or lower extremity persistent joint pain: a cross- sectional study
}

\author{
Garrett Scott Bullock (1D , ${ }^{1,2}$ Gary Collins, ${ }^{3}$ Nicholas Peirce,,${ }^{4,5}$ Nigel K Arden, ${ }^{1,2}$ \\ Stephanie R Filbay (D) ${ }^{2}$
}

To cite: Bullock GS, Collins G, Peirce N, et al. Physical activity and health-related quality of life in former elite and recreational cricketers from the UK with upper extremity or lower extremity persistent joint pain: a cross-sectional study. BMJ Open 2019;9:e032606. doi:10.1136/ bmjopen-2019-032606

- Prepublication history and additional material for this paper are available online. To view these files, please visit the journal online (http://dx.doi. org/10.1136/bmjopen-2019032606).

Received 26 June 2019 Revised 30 September 2019 Accepted 03 0ctober 2019

A) Check for updates

(c) Author(s) (or their employer(s)) 2019. Re-use permitted under CC BY. Published by BMJ.

For numbered affiliations see end of article.

\section{Correspondence to} Dr Garrett Scott Bullock; garrett.bullock@wolfson.ox. ac.uk

\section{ABSTRACT}

Objective To evaluate and compare physical activity (PA) and health-related quality of life (HRQOL) in former elite and recreational cricketers with upper extremity (UE), lower extremity (LE) or no joint pain.

Study design Cross-sectional cohort.

Setting Despite the high prevalence of joint pain in former athletes, the impact of UE pain and LE pain on $\mathrm{PA}$ and $\mathrm{HRQOL}$ and potential differences between former recreational and elite athletes are poorly understood. Participants 703 former cricketers aged $\geq 18$ years (mean age 58.7, SD 12.9, played an average of 30 (IQR 20-40) seasons, $72 \%$ of whom had played at a recreational level) were recruited through the Cricket Health and Wellbeing Study and met eligibility requirements (UE pain, LE pain or no joint pain (defined as pain on most days of the past month)).

Primary and secondary outcomes The International Physical Activity Questionnaire-Short Form collected weekly metabolic equivalents (METS), while the ShortForm 8 collected physical (PCS) and mental (MCS) component scores. Kruskal-Wallis tests with Dunn's posthoc and multivariable linear regressions were performed. Results Weekly METS were similar in former cricketers with UE pain (median (IQR) 2560 (722-4398)), LE pain (2215 (527-3903)) and no pain (2449 (695-4203), $\mathrm{p}=0.39$ ). MCS were similar between groups (UE pain 56.0 (52.1-60.0); LE pain 55.2 (51.1-59.4); no pain 54.7 (50.7-58.7), $p=0.38)$. PCS were more impaired in former cricketers with UE pain (49.8 (44.9-54.8)) or LE pain (46.7 (41.0-51.9)) compared with no pain (54.2 (51.5-56.9), $p<0.0001)$. Former cricketers with LE pain reported worse PCS than those with UE pain $(p=0.04)$. Similar relationships were observed in former elite and recreational cricketers.

Conclusion Despite impaired physical components of HRQOL in former cricketers with UE pain or LE pain, pain was not related to PA levels or mental components of $\mathrm{HRQ}$ oL. Physical components of HRQoL were most impaired in those with LE pain, and findings were similar among former elite and recreational cricketers.
Strengths and limitations of this study

- This study took into account the non-linear relationships between different continuous variables (ie, by using fractional polynomials), where most studies assume linearity.

- Missing data were low, allowing for low bias in a complete case analysis.

- Participants with persistent pain in both the upper and lower extremities and participants with back pain were excluded from the analyses, decreasing the generalisability of these findings.

- The literature on Short-Form 8 minimal detectable difference and minimal clinically important difference is sparse and does not evaluate athletic populations, decreasing the interpretability of these data.

\section{INTRODUCTION}

Upper and lower extremity osteoarthritis (OA) has a high incidence ${ }^{12}$ and a substantial personal and societal burden. ${ }^{3} 4$ Posttraumatic OA occurs at a younger age, with a longer period of disability and less effective treatments than idiopathic OA. ${ }^{5-7}$ Former sport participants have increased posttraumatic OA prevalence compared with the general population, ${ }^{58}$ which is associated with persistent joint pain. ${ }^{9}$ Persistent joint pain is the major cause of patients seeking medical attention for $\mathrm{OA},{ }^{9}$ and has been shown to influence a person's ability to participate in desired forms of activity, ${ }^{10} 11$ which may result in reduced physical activity (PA) levels and negatively impact health-related quality of life (HRQoL). ${ }^{10-13}$

To date, most research investigating $\mathrm{OA}$ and pain has focused on the lower extremity. ${ }^{10-14}$ Former professional soccer players were 


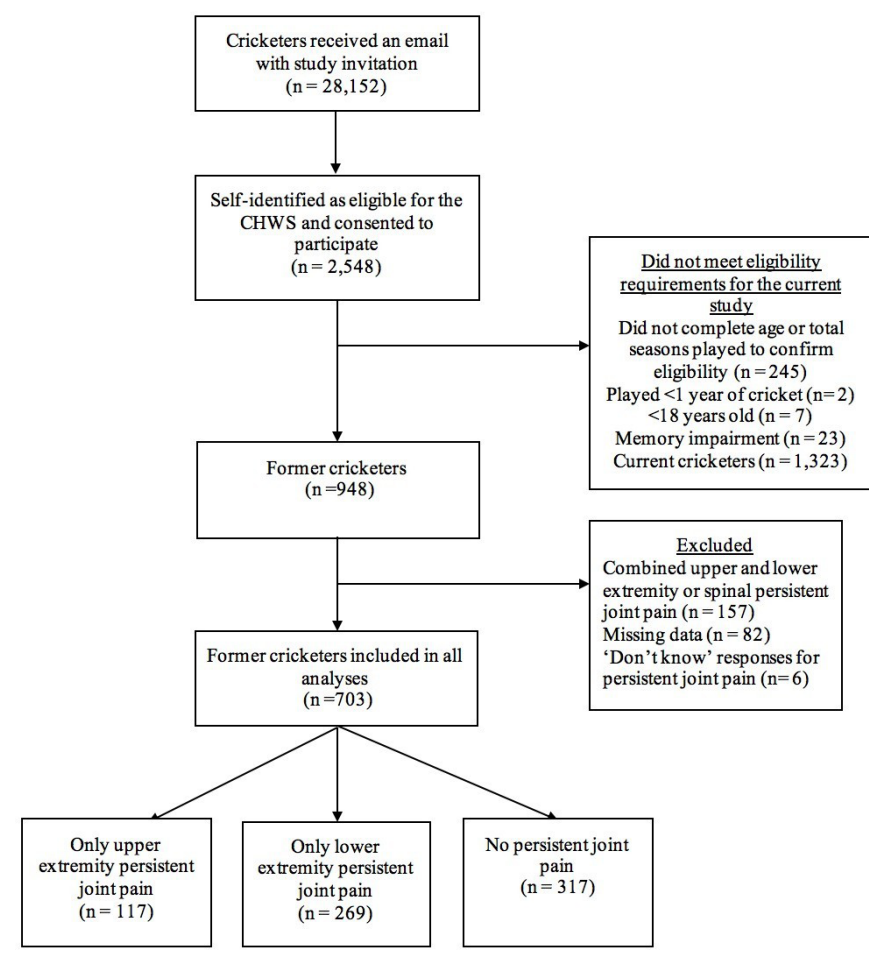

Figure 1 Study flow chart. CHWS, Cricket Health and Wellbeing Study.

found to have a high prevalence of lower extremity $\mathrm{OA}$ and pain compared with controls, ${ }^{1011}$ while former female recreational athletes were found to have two to three times increased hip and knee OA risk compared with population-matched controls. ${ }^{14}$ Lower extremity $\mathrm{OA}$ and pain in former sport participants are associated with impaired function and mobility, increased levels of anxiety and depression, and reduced HRQoL compared with the general population. ${ }^{1012-14}$

Upper extremity pain can have different barriers to PA participation compared with lower extremity pain. ${ }^{15-18}$ For example, lower extremity pain may have a greater effect on jumping, stair use, walking and running. ${ }^{19}{ }^{20}$ In contrast, upper extremity pain can have more effect on specific functional activities such as dressing and eating, ${ }^{15}$ or work-related tasks such as carrying and handling objects, ${ }^{16}$ with potential negative impacts on HRQoL. ${ }^{15}$ Upper extremity pain has been related to reduced PA and function, impaired HRQoL, stress and disability in workers. ${ }^{21-25}$ Despite a high prevalence of upper extremity pain in former throwing-sport participants, ${ }^{26-28}$ the impact of upper extremity pain on PA levels and HRQoL in former athletes is poorly understood.

Psychological characteristics associated with successful high-level athletic performance include resilience, mental toughness and advanced coping skills. ${ }^{29-32}$ Greater resilience and coping strategies can have positive impact on PA levels ${ }^{33-35}$ and HRQoL. ${ }^{34}$ 36-38 Thus, former elite athletes may possess psychological characteristics that enable them to better cope with chronic pain compared with former recreational sport participants, and this could positively impact PA levels and HRQoL.
However, this has not yet been investigated, highlighting the need for further research. It is also not clear if PA levels and HRQoL differ in former sport participants with and without persistent joint pain. The rationale for investigating these relationships in former cricketers was largely due to the high prevalence of upper and lower extremity $\mathrm{OA}$ and persistent pain among former cricketers, ${ }^{12}{ }^{39}$ and our previous qualitative work highlighting that a subgroup of former cricketers experience high quality of life and maintain physically active lifestyles despite persistent joint pain. ${ }^{40}{ }^{41}$ Therefore, the purposes of this study were the following:

- To evaluate the relationship between persistent joint pain (upper extremity, lower extremity or no persistent joint pain), PA levels and HRQoL in former cricketers.

- To compare these relationships in former elite and recreational cricketer subgroups.

\section{METHODS}

\section{Patient and public involvement}

Findings from two qualitative studies investigating the relationship of PA and quality of life in former elite cricketers $^{40}{ }^{41}$ highlighted a need for further research investigating the relationship between cricket participation and health. In collaboration with stakeholders, including governing bodies and current and former cricketers, a questionnaire was developed and refined. This information was disseminated through presentations to stakeholders.

\section{Participants and recruitment}

In March 2017, 28152 current and former cricketers of all playing standards, who were registered on a national database managed by the England and Wales Cricket Board, received an email inviting them to complete an electronic questionnaire. There were 2598 people who believed they met the eligibility requirements outlined in the email and consented to participate in the Cricket Health and Wellbeing Study (figure 1). Participants were eligible for inclusion in the Cricket Health and Wellbeing Study if they had played $\geq 1$ cricket season and were aged $\geq 18$ years. Due to the potential confounding relationship between acute injury and joint pain, ${ }^{42}$ only former cricketers were included in this study. The other eligibility requirement for inclusion in this study was reporting either (1) persistent joint pain only in the upper extremity, (2) persistent joint pain only in the lower extremity or (3) no persistent joint pain (individuals were excluded if they reported persistent back pain, or combined upper and lower extremity persistent joint pain). Participants were also excluded if they reported any memory impairment.

\section{Questionnaire design}

The Cricket Health and Wellbeing Study questionnaire was developed in collaboration with public involvement, and four current/former cricketers piloted the questionnaire. The questionnaire was created to evaluate 
five aspects of health and well-being: (1) cricket-related injury; (2) joint pain and OA; (3) general health and disease prevalence; (4) PA; and (5) resilience, quality of life and flourishing. All participant data were managed and de-identified in a REDCap (Research Electronic Data Capture) software database. The REDCap database was managed by one investigator and pilot-tested by three researchers for errors and overall usability. ${ }^{44}$ The REDCap software ${ }^{44}$ used branching logic and allowed participants the option to save their current progress and complete at a later time. The questionnaire captured data including cricketers' age, body mass index (BMI), number of cricket seasons played, playing standard, presence of comorbidities, persistent pain, medically diagnosed OA, PA and HRQOL.

\section{Outcomes}

Physical activity

The International Physical Activity Questionnaire-Short Form (IPAQ-SF) was used to assess PA. ${ }^{45}$ The IPAQ-SF has been used as a population surveillance and evaluation PA tool. ${ }^{46} 47$ The IPAQ-SF has been observed to have fair agreement with accelerometer data $(0.03-0.39)^{48} 49$ and good validity compared with other PA questionnaires and PA logs $(r>0.50){ }^{49}{ }^{50}$ Participants were asked to recall their PA in a usual week, as time spent in vigorousintensity PA, moderate-intensity PA and walking. ${ }^{45}$ To reduce variability, a standardised approach outlined in the IPAQ-SF manual was used to clean and code the IPAQ-SF data. ${ }^{45}$ In line with recommendations, bouts of weekly PA less than $10 \mathrm{~min}$ were recoded as 0 minutes. ${ }^{45}$ Time spent in vigorous $\mathrm{PA}$, moderate $\mathrm{PA}$ and walking was converted to metabolic equivalents (METS). One MET is $1 \mathrm{kcal} / \mathrm{kg} /$ hour, or the resting metabolic rate, during quiet sitting. ${ }^{45}$ Vigorous PA was calculated as 8 METS per minute, moderate PA was calculated as 4 METS per minute, and walking was calculated as 3.3 METS per minute. ${ }^{45}$ METS were truncated at 3 hours $(180 \mathrm{~min})$ per week, per vigorous, moderate and walking PA. ${ }^{45}$ This was performed in order to reduce participant overestimation effect. ${ }^{45}$ A total of 117 (17\%) participants had PA reports truncated. METS were then combined for vigorous PA, moderate PA and walking, and reported as total weekly METS.

\section{Health-related quality of life}

The Short-Form 8 (SF-8) was used to assess HRQoL. ${ }^{51}$ The SF-8 is a short version of the RAND 36-Item Health Survey (SF-36) V.1.0, ${ }^{52}$ and is scaled and measured on the same point scale $(0-100)$ as the SF-36, with 0 representing maximum disability and 100 representing no disability. ${ }^{53}$ The SF-8 is an eight-item, self-reported HRQoL questionnaire comprising eight domains (general health perceptions, physical function, bodily pain, physical role function, emotional role function, social function, vitality and mental health $)^{53}$ and two component summary scores (physical component score (PCS) and mental component score (MCS)). PCS and MCS have been found to have high reliability $(0.88$ and 0.82 , respectively) in the general US population. ${ }^{54}$ PCS and MCS are calculated using a computerised algorithm and weighted to the US population mean. ${ }^{54} \mathrm{~A}$ score of 50 is considered the population norm, and a score below 47 is considered below the average range of the general population. ${ }^{54}$ The minimum detectable difference for PCS in patients with lower extremity OA is 2 points. ${ }^{55}$ The minimally clinically important difference is estimated to be $3-5$ points in the US general population. ${ }^{56}$

\section{Explanatory variables}

Persistent joint pain

Persistent joint pain was assessed with the following question: 'Do you currently experience pain, discomfort, or have any problems in any of your joints?' If yes, participants were then asked 'Have you had pain in your [left/right] hip/groin, knee, ankle, shoulder, hand/finger, spine/back, other joint on most days of the last month?'. All participants who recorded persistent pain in the 'other joint' category were hand-searched for references of elbow, wrist, foot or toe persistent joint pain. These data were then recorded into separate categories of elbow/wrist and foot/toes persistent joint pain. All persistent joint pain data were then separated into upper extremity persistent joint pain only (shoulder, elbow, wrist, hand and/or fingers), lower extremity persistent joint pain only (hip, knee, ankle, foot and/or toes) and no persistent joint pain. If participants recorded spinal persistent pain or upper and lower extremity persistent joint pain, subjects were excluded from the analyses.

\section{Standard of play}

Standard of play was assessed with the following question: what was the highest standard of cricket that you played for at least one season?'Response options included international, county/premier league, academy or county age group, university, school, village or social, and don't know. Participants were stratified into recreational (university, school, village or social) and elite (international or county/ premier league, academy or county age group). Participants who reported a playing standard as 'Don't know' were excluded from all analyses.

\section{Confounders}

Potential confounders were identified through clinical reasoning and a review of the literature. Confounders included age, BMI and presence of a comorbidity. Participants reported all medical problems that they had been diagnosed with. For the current study, diabetes, stroke and cancer were included as confounders due to a large potential to impact HRQoL and PA levels. ${ }^{57-61}$ Presence of a comorbidity was defined as no comorbidity versus one or more comorbidity.

\section{Statistical analyses}

All data were assessed for missingness prior to analyses. Missing data were calculated as total and percentage of total data (online supplementary appendix 1). Due to the low percentage of missing data (MCS: $8.6 \%$, PCS: $8.4 \%$, 
IPAQ-SF: $5.9 \%$, persistent joint pain: $1.1 \%$ ), a complete case analysis was performed. 'Don't know' responses were excluded from all analyses. The Kruskal-Wallis test was used to compare PA and HRQoL between pain groups. To assess specific group to group differences, a series of Dunn's post-hoc analyses were performed $(p<0.05)$.

Continuous data were not assumed to act linearly on the outcomes. Thus, to evaluate the relationship between persistent joint pain, PA levels and HRQoL, multivariable linear regressions with fractional polynomials were used (to account for the non-linearity of the covariates) ${ }^{62}$ This analysis was repeated in recreational and elite cricketer subgroups to address the second aim of this study. Unadjusted and adjusted coefficients and 95\% CI were calculated. Coefficients were adjusted for the continuous variables age and BMI and the presence of $\geq 1$ comorbidity (yes vs no). All assumptions for fractional polynomial regression were evaluated and satisfied. ${ }^{62}$ Transformations included taking the square root of METS; PCS and MCS were not transformed due to regression residuals. Possible interactions were assessed for inclusion in the model. Interactions explored were between age and BMI, age and comorbidity, BMI and comorbidity, age and persistent pain, BMI and persistent pain, and comorbidity and persistent pain. All analyses were performed in R V.3.5.1 ( $\mathrm{R}$ Core Team (2013); R: A language and environment for statistical computing, R Foundation for Statistical Computing, Vienna, Austria, URL http://www.
R-project.org/), using the dplyr package ${ }^{63}$ for cleaning and coding, the naniar package for missingness assessment, ${ }^{64}$ and the mfp package for fractional polynomial regression. ${ }^{65}$

\section{RESULTS}

A total of 703 former cricketers (aged mean 58.7, SD 12.9 , played an average of 30 (IQR 20-40) seasons, $38 \%$ of whom had played at an elite level) were included in analyses (table 1). BMI in people with upper extremity persistent joint pain was 27.9 (SD 5.0), lower extremity persistent joint pain was 29.1 (SD 5.5) and in people with no persistent joint pain was 27.8 (SD 5.4).

\section{A comparison of PA and HRQOL between former cricketers with upper extremity persistent joint pain, lower extremity persistent joint pain and no persistent joint pain}

For a visual representation of the PA data, please refer to figure 2. Kruskal-Wallis test indicated that there was no difference in PA levels between former cricketers with upper extremity persistent joint pain (median (IQR): 2560 (722-4398) METS), lower extremity persistent joint pain (2215 (527-3903) METS) or no persistent joint pain (2449 (695-4203) METS) $\left(\chi^{2}: 1.91, \mathrm{p}=0.39\right)$. There were significant PCS differences between pain groups $(\mathrm{p}<0.001)$. Post-hoc tests demonstrated that former cricketers reported worse PCS if they had persistent joint

Table 1 Participant characteristics

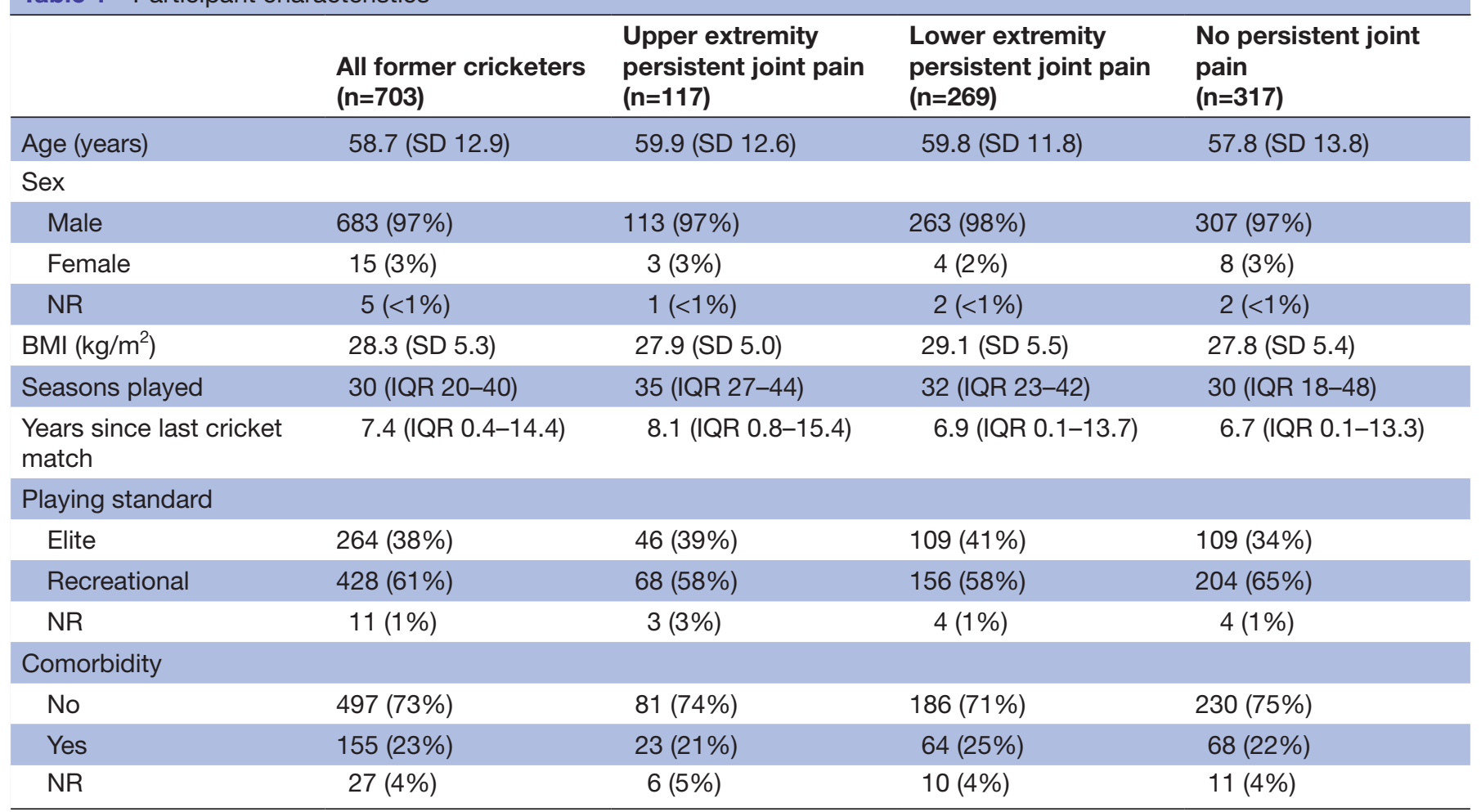

Participants reported the highest standard they had played for at least one season and then were stratified into recreational (university, school, village or social) and elite (international or county/premier league, academy or county age group).

BMI, body mass index; NR, no response. 

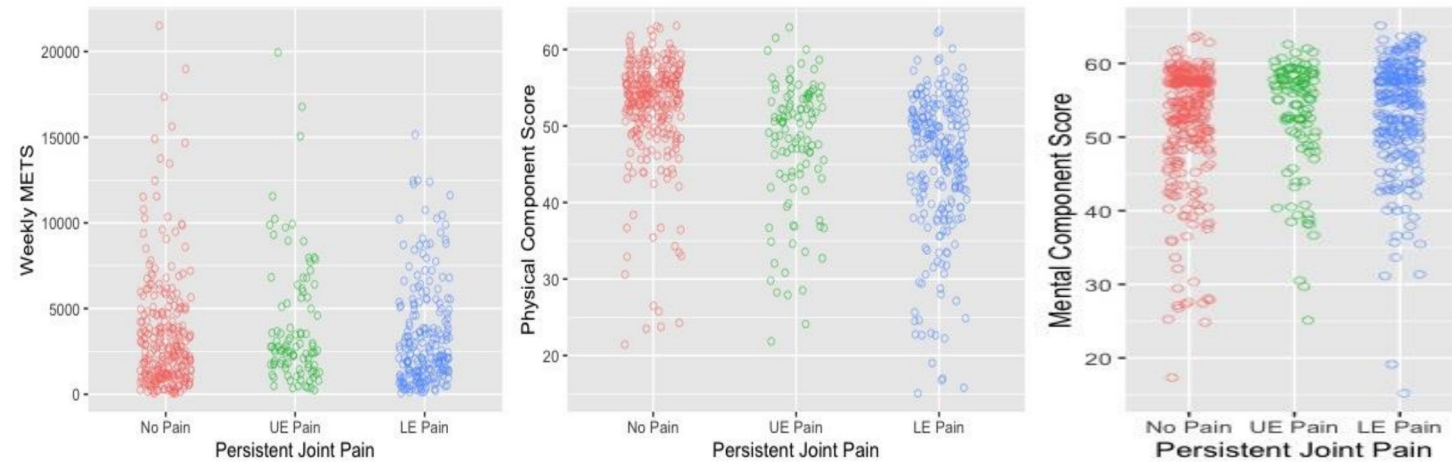

Persistent Joint Pain

No Pain

UE Pain

LE Pain

Figure 2 Weekly physical activity levels and health-related quality of life in former cricketers with upper extremity persistent joint pain, lower extremity persistent joint pain or no persistent joint pain. LE, lower extremity; METS, metabolic equivalents; UE, upper extremity.

pain in the upper extremity (PCS: 49.8 (44.9-54.8)) or lower extremity (PCS: 46.7 (41.0-51.9)), compared with former cricketers with no persistent joint pain (PCS: 54.2 $(51.5-56.9))\left(\chi^{2}: 121.2, \mathrm{p}<0.001\right)$. Former cricketers with lower extremity persistent joint pain reported worse PCS compared with former cricketers with upper extremity persistent joint pain (median difference: 1.8, $\mathrm{p}=0.04$ ). MCS were similar between individuals with upper extremity persistent joint pain (56.0 (52.1-60.0)), lower extremity persistent joint pain (55.2 (51.1-59.4)) and no persistent joint pain $(54.7(50.7-58.7))\left(\chi^{2}: 1.92, \mathrm{p}=0.38\right)$.

\section{The relationship between persistent joint pain, PA and HRQoL}

Multivariable linear regressions found that persistent joint pain was not related to PA levels (upper extremity: adjusted effect (95\% CI): 28.1 METS (-1.1 to 135.7$)$; lower extremity: 4.6 METS ( -7.5 to 49.4$)$; see table 2$)$.
Former cricketers with upper extremity persistent joint pain reported an estimated -5.5 ( -7.4 to -3.5$)$ points lower (worse) PCS than cricketers without persistent joint pain. Former cricketers with lower extremity persistent joint pain reported an estimated -6.6 (-8.1 to -5.2$)$ points lower PCS compared with those with no persistent joint pain (table 2). Persistent joint pain was not associated with MCS (upper extremity: -0.1 ( $(-0.2$ to 0.1$)$; lower extremity: $-0.1(-0.2$ to 0.1$))$.

\section{Elite versus recreational cricketer subgroup analysis}

Multivariable linear regressions found that findings were similar between recreational and elite cricketer subgroups (table 3). Persistent joint pain was not associated with PA and MCS, and PCS were impaired in both former elite and recreational cricketers with upper extremity (adjusted effect $(95 \% \mathrm{CI})$ elite: -5.3 ( -8.8 to -1.9$)$; recreational:

Table 2 Relationship between persistent joint pain, physical activity and health-related quality of life

\begin{tabular}{|c|c|c|c|c|c|c|}
\hline & \multicolumn{2}{|l|}{ Weekly METSף } & \multicolumn{2}{|l|}{ PCS $^{\star *}$} & \multicolumn{2}{|l|}{ MCS $^{\star *}$} \\
\hline & $\begin{array}{l}\text { Unadjusted } \\
\text { effect* }^{\star} \\
(95 \% \mathrm{Cl})\end{array}$ & $\begin{array}{l}\text { Adjusted† } \\
\text { effect* }^{*} \\
(95 \% \mathrm{Cl})\end{array}$ & $\begin{array}{l}\text { Unadjusted } \\
\text { effect } \\
(95 \% \mathrm{Cl})\end{array}$ & $\begin{array}{l}\text { Adjusted† } \\
\text { effect } \neq \\
(95 \% \mathrm{Cl})\end{array}$ & $\begin{array}{l}\text { Unadjusted } \\
\text { effect } \\
(95 \% \mathrm{Cl})\end{array}$ & $\begin{array}{l}\text { Adjusted† } \\
\text { effect } \\
(95 \% \mathrm{Cl})\end{array}$ \\
\hline $\begin{array}{l}\text { Upper extremity } \\
\text { persistent joint } \\
\text { pain§ }\end{array}$ & $\begin{array}{l}20.3 \\
(-3.2 \text { to } 117) \\
p=0.83\end{array}$ & $\begin{array}{l}28.1 \\
(-1.1 \text { to } 136) \\
p=0.10\end{array}$ & $\begin{array}{l}-5.4 \\
(-7.3 \text { to } 3.6), \\
p<0.001\end{array}$ & $\begin{array}{l}-5.5 \\
(-7.4 \text { to } 3.5) \\
p<0.001\end{array}$ & $\begin{array}{l}-0.1 \\
(-0.2 \text { to } 0.1), \\
p=0.35\end{array}$ & $\begin{array}{l}-0.1 \\
(-0.2 \text { to } 0.1), \\
p=0.26\end{array}$ \\
\hline $\begin{array}{l}\text { No persistent } \\
\text { joint pain }\end{array}$ & Reference group & & Reference group & & Reference group & \\
\hline
\end{tabular}

*Participants with memory impairments were excluded from the analyses.

†Estimates are adjusted for age, body mass index and comorbidities.

$\ddagger$ Comorbidities were defined as none present $(0)$ and presence of at least one comorbidity (1). Comorbidities included were diabetes, stroke, skin cancer and other cancer.

§Upper extremity (shoulder, elbow, wrist or hand) and lower extremity (hip, knee or ankle) persistent joint pain were assessed by asking individuals if they had joint-specific pain on 'most days of the last month'.

IShort-form questionnaire (International Physical Activity Questionnaire-Short Form). Physical activity was calculated as METS per week; METS were transformed prior to analysis by taking the square root and then retransformed by squaring after analysis.

${ }^{* *}$ Short-Form 8 Health Survey. PCS and MCS were calculated using norm-based scoring (population norm 50, SD 10, high scorer=better health-related quality of life).

MCS, mental component score; METS, metabolic equivalents; PCS, physical component score. 
Table 3 Relationship between persistent joint pain, physical activity and health-related quality of life in former recreational and elite cricketer subgroups

\begin{tabular}{|c|c|c|c|c|c|c|}
\hline & \multicolumn{2}{|l|}{ Weekly METS } & \multicolumn{2}{|l|}{ PCS } & \multicolumn{2}{|l|}{ MCS } \\
\hline & $\begin{array}{l}\text { Unadjusted } \\
\text { effect* }^{*} \\
(95 \% \mathrm{Cl})\end{array}$ & $\begin{array}{l}\text { Adjusted† } \\
\text { effect* }^{*} \\
(95 \% \mathrm{Cl})\end{array}$ & $\begin{array}{l}\text { Unadjusted } \\
\text { effect } \\
(95 \% \mathrm{Cl})\end{array}$ & $\begin{array}{l}\text { Adjusted† } \\
\text { effect } \neq \\
(95 \% \mathrm{Cl})\end{array}$ & $\begin{array}{l}\text { Unadjusted } \\
\text { effect } \\
(95 \% \mathrm{Cl})\end{array}$ & $\begin{array}{l}\text { Adjusted } † \\
\text { effect } \neq \\
(95 \% \mathrm{Cl})\end{array}$ \\
\hline \multicolumn{7}{|c|}{$\begin{array}{l}\text { Former elite cricketers } \\
(n=280)\end{array}$} \\
\hline $\begin{array}{l}\text { Upper } \\
\text { extremity } \\
\text { persistent } \\
\text { joint pain }\end{array}$ & $\begin{array}{l}70 \\
(-1.6 \text { to } 324), \\
p=0.09\end{array}$ & $\begin{array}{l}88 \\
(-0.1 \text { to } 356), \\
p=0.05\end{array}$ & $\begin{array}{l}-5.3 \\
(-8.6 \text { to } 2.0) \\
p=0.001\end{array}$ & $\begin{array}{l}-5.3 \\
(-8.8 \text { to } 1.9) \\
p=0.002\end{array}$ & $\begin{array}{l}0.055 \\
(-2.3 \text { to } 3.4), \\
p=0.70\end{array}$ & $\begin{array}{l}5.3 \\
(-1.1 \text { to } 11.7), \\
p=0.10\end{array}$ \\
\hline $\begin{array}{l}\text { Lower } \\
\text { extremity } \\
\text { persistent } \\
\text { joint pain }\end{array}$ & $\begin{array}{l}5.2 \\
(-28 \text { to } 97), \\
p=0.56\end{array}$ & $\begin{array}{l}8.2 \\
(-21 \text { to } 106), \\
p=0.45\end{array}$ & $\begin{array}{l}-7.5 \\
(-10.1 \text { to } 4.9) \\
p<0.001\end{array}$ & $\begin{array}{l}-7.0 \\
(-9.7 \text { to } 4.3) \\
p<0.001\end{array}$ & $\begin{array}{l}0.1 \\
(-1.7 \text { to } 2.7) \\
p=0.64\end{array}$ & $\begin{array}{l}2.2 \\
(-2.7 \text { to } 7.0), \\
p=0.39\end{array}$ \\
\hline $\begin{array}{l}\text { Upper } \\
\text { extremity } \\
\text { persistent } \\
\text { joint pain }\end{array}$ & $\begin{array}{l}5.6 \\
(-37 \text { to } 117), \\
p=0.58\end{array}$ & $\begin{array}{l}10.5 \\
(-29 \text { to } 149), \\
p=0.47\end{array}$ & $\begin{array}{l}-5.6 \\
(-7.9 \text { to } 3.3), \\
p<0.001\end{array}$ & $\begin{array}{l}-5.8 \\
(-8.1 \text { to } 3.4) \\
p<0.001\end{array}$ & $\begin{array}{l}0.8 \\
(-1.5 \text { to } 3.0) \\
p=0.50\end{array}$ & $\begin{array}{l}1.1 \\
(-1.1 \text { to } 3.2), \\
p=0.35\end{array}$ \\
\hline $\begin{array}{l}\text { Lower } \\
\text { extremity } \\
\text { persistent } \\
\text { joint pain }\end{array}$ & $\begin{array}{l}-0.7 \\
(-49 \text { to } 29) \\
p=0.83\end{array}$ & $\begin{array}{l}1.8 \\
(-26 \text { to } 61), \\
p=0.68\end{array}$ & $\begin{array}{l}-6.6 \\
(-8.3 \text { to } 4.9), \\
p<0.001\end{array}$ & $\begin{array}{l}-6.2 \\
(-8.0 \text { to } 4.5) \\
p<0.001\end{array}$ & $\begin{array}{l}-0.8 \\
(-1.1 \text { to } 2.7) \\
p=0.33\end{array}$ & $\begin{array}{l}1.2 \\
(-0.5 \text { to } 2.8) \\
p=0.17\end{array}$ \\
\hline $\begin{array}{l}\text { No persistent } \\
\text { joint pain }\end{array}$ & Reference group & & Reference group & & Reference group & \\
\hline
\end{tabular}

*Participants with memory impairments were excluded from the analyses.

†Estimates are adjusted for age, body mass index and comorbidities.

$\ddagger$ Comorbidities were defined as not present (0) and presence of at least one comorbidity (1). Comorbidities included were diabetes, stroke, skin cancer and other cancer.

§Upper extremity (shoulder, elbow, wrist or hand) and lower extremity (hip, knee or ankle) persistent joint pain were assessed by asking individuals if they had joint-specific pain on 'most days of the last month'.

IShort-form questionnaire (International Physical Activity Questionnaire-Short Form). Physical activity was calculated as METS per week; METS were transformed prior to analysis by taking the square root and then retransformed by squaring after analysis.

${ }^{* *}$ Short-Form 8 Health Survey. PCS were calculated using norm-based scoring (population norm 50, SD 10, high scorer=better health-related quality of life). MCS were calculated using norm-based scoring (population norm 50, SD 10, high scorer=better health-related quality of life). MCS, mental component score; METS, metabolic equivalents; PCS, physical component score.

$-5.8(-8.1$ to -3.4$))$ or lower extremity (elite: $-7.0(-9.7$ to -4.3$)$; recreational: $-6.2(-8.0$ to -4.5$))$ persistent joint pain, compared with their counterparts with no persistent joint pain (table 3 ).

\section{DISCUSSION}

Surprisingly, despite impaired PCS, there was no difference in weekly PA or MCS between former cricketers with upper or lower extremity persistent joint pain and those with no persistent joint pain. Additionally, former cricketers with lower extremity persistent joint pain reported worse physical components of HRQoL than those with upper extremity persistent joint pain. We also found that the relationship between joint pain, PA and HRQoL was similar among former elite and recreational cricketer subgroups.

Former cricketers with persistent joint pain did not report reduced weekly $\mathrm{PA}$ compared with former cricketers without persistent joint pain. In the general population, people with OA have reduced PA levels compared with matched controls without $\mathrm{OA}^{66}$ In this study, former cricketers with and without persistent joint pain had higher PA levels compared with the general population. ${ }^{67-69}$ Former cricketers reported median daily PA levels of 120 METS per day; this is in comparison with an average range of 41-50 METS per day for European men. ${ }^{67-69}$ Former cricketers may find alternative strategies to exercise, despite persistent joint pain. ${ }^{41}{ }^{70}$ In a qualitative study, former cricketers with pain and physical 
impairment found alternative strategies to perform PA and shared specific psychological strengths that may enable them to effectively cope with joint pain. ${ }^{41}$ Intrinsic motivation, ${ }^{71}$ higher levels of resilience ${ }^{32} 40$ and effective coping strategies ${ }^{40} 41$ are all characteristics common among successful athletes. Such psychological strengths may be more common in former sport participants compared with the general population. ${ }^{29-32}$ Additionally, sport participants may be encouraged to play through pain $^{72}$ and are often rewarded for doing so. ${ }^{73}$ Such pain behaviours could influence how former sport participants perceive and cope with joint pain. Pain behaviours and psychological strengths common among sport participants could provide a potential explanation for the high PA levels in former cricketers living with joint pain. Further research is required to understand the potential interplay between persistent pain, psychological characteristics and PA in former athletes.

The psychological strengths that are common among former sports participants, including resilience, ${ }^{32} 40$ mental toughness ${ }^{7475}$ and pain coping strategies, ${ }^{4075}$ could also provide a potential explanation for why MCS were not impaired in former cricketers with persistent joint pain, despite impaired PCS. In a recent meta-analysis, former athletes with impaired PCS reported greater MCS compared with general population norms. ${ }^{76}$ In a typical OA population, both PCS and MCS are impaired, ${ }^{77}$ suggesting HRQoL in former sport participants with OA may differ from the typical OA population. Furthermore, the high PA levels in former cricketers in our study could also contribute to the high MCS. PA has been shown to have a protective effect against depression and a positive impact on the mental components of HRQoL in the general population, older adults and in former elite athletes. ${ }^{78-81}$ Irrespective of joint pain, former cricketers reported MCS of 5-6 points better than the population normative average, and this difference is likely to be clinically meaningful. ${ }^{82}$

Former cricketers with persistent joint pain had impaired physical components of HRQoL compared with cricketers without persistent pain. This supports previous literature which found impaired PCS in former collegiate $^{83-85}$ and professional athletes ${ }^{86}$ compared with non-athlete controls. Former cricketers with persistent pain reported PCS of 5-7 points lower than former cricketers without persistent pain, demonstrating a clinically important difference between persistent pain and no pain groups. Impaired physical components of HRQoL in former athletes have been attributed to poor joint health ${ }^{83-85}$ which may be due to previous musculoskeletal injury. ${ }^{87-89}$ Former athletes with a history of musculoskeletal injury report worse physical components of HRQoL than former athletes without a history of injury ${ }^{87}$ and the general population. ${ }^{88}{ }^{89}$ In our study, former cricketers without persistent pain reported a median PCS of 4 points above the population normative mean of 50, suggesting that former cricket participants without joint pain have greater levels of physical functioning compared with the general population. Importantly, despite impaired PCS in former cricketers with persistent pain, MCS were not impaired. This highlights the importance of selecting an HRQoL measure that differentiates assessment of pain and physical function from assessment of mental health and well-being when evaluating HRQoL in former sport participants.

Cricketers with persistent lower extremity pain reported 3.1 points worse PCS compared with cricketers with upper extremity pain, and this difference is likely to be clinically meaningful. ${ }^{82}$ Worse PCS in former cricketers with lower extremity pain may be due to greater difficulties performing usual PAs (such as difficulties with ambulation and stair navigation ${ }^{90}$ ) or experiencing more severe bodily pain than those who report upper extremity pain. For example, former collegiate athletes with lower extremity persistent pain were 2.5 times more likely to be limited in physical function, such as stair navigation, and have greater impaired HRQoL, compared with nonathletes. ${ }^{84}$ While there is research investigating the impacts of lower extremity pain on function in former athletes, our understanding of the impact of upper extremity pain on function in former athletes is poor. Further research could inform strategies to improve physical components of HRQoL among former athletes with persistent upper extremity pain.

The relationship between persistent joint pain, PA and HRQoL was similar between elite and recreational former cricketers. Few studies have investigated PA or HRQoL in former athletes from different standards of play. Higher standards of sport competition require elevated levels of resilience and psychological hardiness due to the increased levels of training and competition. ${ }^{29-32} 92$ Despite the observed psychological strengths associated with elite cricket participation, any level of sport participation is associated with favourable psychological strengths such as resilience. ${ }^{30} 3292$ Thus, it is possible that all standards of cricket participation are associated with psychological benefits that may explain the high PA levels and mental components of HRQoL in former cricketers living with persistent pain; further research is needed to explore this possibility.

\section{Strengths and potential limitations}

This study took into account the non-linear relationships between different continuous variables (ie, by using fractional polynomials), where most studies assume linearity. ${ }^{93}$ Missing data were low, decreasing the risk of bias in a complete case analysis. PA was truncated above $180 \mathrm{~min}$, which may introduce a ceiling effect. Further, PA recall may not be as precise as PA monitors, which may introduce measurement error, and social desirability may cause PA overestimation. ${ }^{94}{ }^{95}$ Persistent joint pain was assessed by asking cricketers if they had joint pain on most days of the last month, which is based on the National Health and Nutrition Examination Survey. However, joint pain may occur intermittently and still affect PA and HRQoL. As a result, this study may have missed participants with 
significant pain. Participants with persistent pain in both the upper and lower extremities and participants with back pain were excluded from the analyses. This limits the scope of this study to participants with only upper or lower extremity persistent pain, or no persistent pain, decreasing the generalisability of these findings. The literature on SF-8 minimal detectable difference and minimal clinically important difference is sparse and does not evaluate athletic populations. This decreases the interpretability of these data. There is also the possibility of bias due to unmeasured confounding. Potential confounders that were not measured in this study include socioeconomic status and other sports played, which both have been observed to be related to HRQoL. ${ }^{76} 9697$ These discrepancies may decrease the generalisability of these findings. Potential participants were informed of the inclusion and exclusion criteria during recruitment and were able to self-select eligibility to participate. Due to this recruitment strategy, it is not possible to determine the questionnaire response rate nor responder bias. This recruitment strategy may decrease the generalisability of these findings.

\section{CONCLUSIONS}

Physical components of HRQoL were impaired in former cricketers with persistent joint pain compared with those without joint pain, and PCS were more impaired in those with lower extremity pain compared with those with upper extremity pain. However, former cricketers with persistent joint pain did not have reduced PA levels or mental components of HRQoL, compared with those with no persistent joint pain. These relationships were similar among former elite and recreational cricketers. These results highlight the need to select an HRQoL measure that differentiates assessment of pain and physical functional from assessment of mental health and well-being when evaluating HRQoL in former sport participants. The high average PA levels among former cricketers with persistent joint pain could explain the high MCS in this group. In contrast, former cricketers with joint pain who are physically inactive may benefit from targeted strategies to increase activity levels, with potential to positively impact quality of life. Further research is needed to determine whether the psychological benefits of sport participation explain why former cricketers had high PA levels and mental components of HRQoL, despite living with persistent joint pain.

\footnotetext{
Author affiliations

${ }^{1}$ Nuffield Department of Orthopaedics, Rheumatology and Musculoskeletal Sciences, University of Oxford, Oxford, UK

${ }^{2}$ Arthritis Research UK Centre for Sport, Exercise and Osteoarthritis, Nuffield Department of Orthopaedics, Rheumatology and Musculoskeletal Sciences, University of Oxford, Oxford, UK

${ }^{3}$ Centre for Statistics in Medicine, University of Oxford, Oxford, UK

${ }^{4}$ Centre For Sports Medicine, Nottingham University Hospitals Trust, Nottingham, UK

${ }^{5}$ National Cricket Performance Centre, England and Wales Cricket Board,

Loughborough, UK
}

Twitter Stephanie R Filbay @stephfilbay

Contributors GSB, GC, NP, NKA, SRF conceived the study idea. GSB, GC, NP, NKA, SRF were involved in methodological design and planning. GSB and SRF wrote the first draft of the manuscript. GSB, GC, SRF contributed to statistical analyses. GSB, GC, NP, NKA, SRF all critically revised the manuscript. GSB, GC, NP, NKA, SRF all approved the final version of the manuscript.

Funding This study was funded by the Centre for Sport, Exercise and Osteoarthritis Research Versus Arthritis (grant reference 21595). GC was supported by the NIHR Biomedical Research Centre, 0xford.

Competing interests None declared.

Patient consent for publication Not required.

Ethics approval This cross-sectional study was approved by the NHS Health Research Authority (NRES), London Stanmore Research Ethics Committee (REC 15/ LO/1274).

Provenance and peer review Not commissioned; externally peer reviewed. Data availability statement Data are available upon reasonable request.

Open access This is an open access article distributed in accordance with the Creative Commons Attribution 4.0 Unported (CC BY 4.0) license, which permits others to copy, redistribute, remix, transform and build upon this work for any purpose, provided the original work is properly cited, a link to the licence is given, and indication of whether changes were made. See: https://creativecommons.org/ licenses/by/4.0/.

ORCID iDs

Garrett Scott Bullock http://orcid.org/0000-0003-0236-9015

Stephanie R Filbay http://orcid.org/0000-0002-9624-0791

\section{REFERENCES}

1 Plotnikoff R, Karunamuni N, Lytvyak E, et al. Osteoarthritis prevalence and modifiable factors: a population study. BMC Public Health 2015;15:1195.

2 van Schoor NM, Zambon S, Castell MV, et al. Impact of clinical osteoarthritis of the hip, knee and hand on self-rated health in six European countries: the European project on osteoarthritis. Qual Life Res 2016;25:1423-32.

3 Palazzo C, Nguyen C, Lefevre-Colau M-M, et al. Risk factors and burden of osteoarthritis. Ann Phys Rehabil Med 2016;59:134-8.

4 Cross M, Smith E, Hoy D, et al. The global burden of hip and knee osteoarthritis: estimates from the global burden of disease 2010 study. Ann Rheum Dis 2014;73:1323-30.

5 Carbone A, Rodeo S. Review of current understanding of posttraumatic osteoarthritis resulting from sports injuries. J Orthop Res 2017;35:397-405.

6 Brown TD, Johnston RC, Saltzman CL, et al. Posttraumatic osteoarthritis: a first estimate of incidence, prevalence, and burden of disease. J Orthop Trauma 2006;20:739-44.

7 Vannini F, Spalding T, Andriolo L, et al. Sport and early osteoarthritis: the role of sport in aetiology, progression and treatment of knee osteoarthritis. Knee Surgery, Sports Traumatology, Arthroscopy 2016;24:1786-96.

8 Whittaker JL, Woodhouse LJ, Nettel-Aguirre A, et al. Outcomes associated with early post-traumatic osteoarthritis and other negative health consequences 3-10 years following knee joint injury in youth sport. Osteoarthritis Cartilage 2015;23:1122-9.

9 Neogi T. The epidemiology and impact of pain in osteoarthritis. Osteoarthritis Cartilage 2013;21:1145-53.

10 Arliani GG, Astur DC, Yamada RKF, et al. Early osteoarthritis and reduced quality of life after retirement in former professional soccer players. Clinics 2014;69:589-94.

11 Turner AP, Barlow JH, Heathcote-Elliott C. Long term health impact of playing professional football in the United Kingdom. Br J Sports Med 2000;34:332-6.

12 Jones ME, Davies MAM, Leyland KM, et al. Osteoarthritis and other long-term health conditions in former elite cricketers. J Sci Med Sport 2018;21:558-63.

13 Davies MAM, D Judge A, Delmestri A, et al. Health amongst former rugby union players: a cross-sectional study of morbidity and healthrelated quality of life. Sci Rep 2017;7:11786.

14 Spector TD, Harris PA, Hart DJ, et al. Risk of osteoarthritis associated with long-term weight-bearing sports: a radiologic survey of the hips and knees in female ex-athletes and population controls. Arthritis Rheum 1996;39:988-95. 
15 Lang CE, Bland MD, Bailey RR, et al. Assessment of upper extremity impairment, function, and activity after stroke: foundations for clinical decision making. J Hand Ther 2013;26:104-15.

16 Shaw WS, Feuerstein M, Lincoln AE, et al. Ergonomic and psychosocial factors affect daily function in workers' compensation claimants with persistent upper extremity disorders. J Occup Environ Med 2002;44:606-15.

17 Peters SE, Johnston V, Ross M, et al. Expert consensus on facilitators and barriers to return-to-work following surgery for nontraumatic upper extremity conditions: a Delphi study. J Hand Surg Eur Vol 2017;42:127-36.

18 Hundza S, Quartly C, Kim JM, et al. Similar barriers and facilitators to physical activity across different clinical groups experiencing lower limb spasticity. Disabil Rehabil 2016;38:1370-81.

19 Barnes KR, Mcguigan MR, Kilding AE. Lower-body determinants of running economy in male and female distance runners. J Strength Cond Res 2014;28:1289-97.

20 Vogt MT, Lauerman WC, Chirumbole M, et al. A community-based study of postmenopausal white women with back and leg pain: health status and limitations in physical activity. The Journals of Gerontology Series A: Biological Sciences and Medical Sciences 2002:57:M544-50.

21 Montero A, Mulero J-F, Tornero C, et al. Pain, disability and healthrelated quality of life in osteoarthritis-joint matters: an observational, multi-specialty trans-national follow-up study. Clin Rheumato 2016;35:2293-305.

22 Verma C, Parikh R, Nadkar M, et al. Correlation of functional ability of the hand with upper limb function and quality of life in patients with rheumatoid arthritis. J Assoc Physicians India 2017;65:20-4.

23 Rincón-Hurtado Ángela Maria, Rocha-Buelvas A, López-Cardona $A$, et al. Health-Related quality of life of patients with rotator cuff injuries, Cofee triangle, Colombia, 2013. Rev Bras Ortop 2018;53:364-72.

24 Cassou B, Derriennic F, Monfort C, et al. Chronic neck and shoulder pain, age, and working conditions: longitudinal results from a large random sample in France. Occup Environ Med 2002;59:537-44.

25 Grzywacz JG, Arcury TA, Mora D, et al. Work organization and musculoskeletal health: clinical findings from immigrant Latino poultry processing and other manual workers. J Occup Environ Med 2012;54:995-1001.

26 Sauers EL, Dykstra DL, Bay RC, et al. Upper extremity injury history, current pain rating, and health-related quality of life in female softbal pitchers. J Sport Rehabil 2011;20:100-14.

27 Soomro N, Strasiotto L, Sawdagar T, et al. Cricket injury epidemiology in the twenty-first century: what is the burden? Sports Med 2018;48:2301-16.

28 Posner M, Cameron KL, Wolf JM, et al. Epidemiology of major league baseball injuries. Am J Sports Med 2011;39:1675-91.

29 Cowden RG, Fuller DK, Anshel MH. Psychological predictors of mental toughness in elite tennis: an exploratory study in learned resourcefulness and competitive trait anxiety. Percept Mot Skills 2014;119:661-78.

30 Secades XG, Molinero O, Salguero A, et al. Relationship between resilience and coping strategies in competitive sport. Percept Mot Skills 2016;122:336-49.

31 Shields MR, Brooks MA, Koltyn KF, et al. Cognitive resilience and psychological responses across a collegiate Rowing season. Med Sci Sports Exerc 2017;49:2276-85.

32 Sarkar M, Fletcher D. Psychological resilience in sport performers: a review of stressors and protective factors. J Sports Sci 2014;24:1-16.

33 Wermelinger Ávila MP, Corrêa JC, Lucchetti ALG, et al. The role of physical activity in the association between resilience and mental health in older adults. J Aging Phys Act 2018;26:248-53.

34 Taylor K, Scruggs PW, Balemba OB, et al. Associations between physical activity, resilience, and quality of life in people with inflammatory bowel disease. Eur J Appl Physiol 2018;118:829-36.

35 Seaton CL, Bottorff JL, Jones-Bricker M, et al. The role of positive emotion and Ego-Resilience in determining men's physical activity following a workplace health intervention. Am J Mens Health 2018;12:1916-28.

36 Lee I-M, Lee I-M, Leung R. Physical activity and personal characteristics associated with depression and suicide in American College men. Acta Psychiatr Scand 1994;89:16-22.

37 Camacho TC, Roberts RE, Lazarus NB, et al. Physical activity and depression: evidence from the Alameda County study. Am J Epidemiol 1991;134:220-31.

38 Farmer ME, Locke BZ, Mościcki EK, et al. Physical activity and depressive symptoms: the NHANES I epidemiologic follow-up study. Am J Epidemiol 1988;128:1340-51.
39 Jones ME, Davies MA, Leyland KM, et al. The association of previous injury with joint pain, osteoarthritis, and joint replacement across all joints in former elite English cricketers. Osteoarthritis Cartilage 2017;25:S200-1.

40 Filbay SR, Bishop F, Peirce N, et al. Common attributes in retired professional cricketers that may enhance or hinder quality of life after retirement: a qualitative study. BMJ Open 2017;7:e016541.

41 Filbay SR, Bishop FL, Peirce N, et al. Physical activity in former elite cricketers and strategies for promoting physical activity after retirement from cricket: a qualitative study. BMJ Open 2017;7:e017785.

42 Igolnikov I, Gallagher RM, Hainline B. Sport-Related injury and pain classification. Handb Clin Neurol 2018;158:423-30.

43 Harris PA, Taylor R, Thielke R, et al. Research electronic data capture (REDCap)--a metadata-driven methodology and workflow process for providing translational research informatics support. J Biomed Inform 2009;42:377-81.

44 Lyon JA, Garcia-Milian R, Norton HF, et al. The use of research electronic data capture (REDCap) software to create a database of librarian-mediated literature searches. Med Ref Serv $Q$ 2014;33:241-52

45 Committee IR. Guidelines for data processing and analysis of the International Physical Activity Questionnaire (IPAQ)-short and long forms, 2005. Available: http://www ipaq ki se/scoring pdf

46 Rosemann T, Kuehlein T, Laux G, et al. Osteoarthritis of the knee and hip: a comparison of factors associated with physical activity. Clin Rheumatol 2007;26:1811-7.

47 Hultenheim Klintberg I, Karlsson J, Svantesson U. Health-Related quality of life, patient satisfaction, and physical activity 8-11 years after arthroscopic subacromial decompression. J Shoulder Elbow Surg 2011;20:598-608.

48 Ekelund U, Sepp H, Brage S, et al. Criterion-related validity of the last 7-day, short form of the International physical activity questionnaire in Swedish adults. Public Health Nutr 2006;9:258-65

49 Mäder U, Martin BW, Schutz Y, et al. Validity of four short physical activity questionnaires in middle-aged persons. Med Sci Sports Exerc 2006;38:1255-66.

50 Macfarlane DJ, Lee CCY, Ho EYK, et al. Convergent validity of six methods to assess physical activity in daily life. J Appl Physiol 2006;101:1328-34

51 Turner-Bowker DM, Bayliss MS, Ware JE, et al. Usefulness of the SF-8 health survey for comparing the impact of migraine and other conditions. Qual Life Res 2003;12:1003-12.

52 Hays RD, Sherbourne CD, Mazel RM. The Rand 36-Item health survey 1.0. Health Econ 1993;2:217-27.

53 Ware JE, Sherbourne CD. The mos 36-item short-form health survey (SF-36). I. conceptual framework and item selection. Med Care 1992;30:473-83.

54 Ware JE, Kosinski M, Dewey JE, et al. How to score and interpret single-item health status measures: a manual for users of the SF-8 ${ }^{\mathrm{TM}}$ health survey. RI: QualityMetric Incorporated 2001;15

55 Angst F, Aeschlimann A, Stucki G. Smallest detectable and minimal clinically important differences of rehabilitation intervention with their implications for required sample sizes using WOMAC and SF-36 quality of life measurement instruments in patients with osteoarthritis of the lower extremities. Arthritis Rheum 2001;45:384-91.

56 Samsa G, Edelman D, Rothman ML, et al. Determining clinically important differences in health status measures. Pharmacoeconomics 1999;15:141-55.

57 Mols F, Vingerhoets AJJM, Coebergh JW, et al. Quality of life among long-term breast cancer survivors: a systematic review. Eur J Cancer 2005;41:2613-9.

58 Doyle C, Kushi LH, Byers T, et al. Nutrition and physical activity during and after cancer treatment: an American cancer Society guide for informed choices. CA Cancer J Clin 2006;56:323-53.

59 Manson JE, Stampfer MJ, Colditz GA, et al. Physical activity and incidence of non-insulin-dependent diabetes mellitus in women. The Lancet 1991;338:774-8.

60 Goldney RD, Phillips PJ, Fisher LJ, et al. Diabetes, depression, and quality of life: a population study. Diabetes Care 2004;27:1066-70.

61 Moore SA, Hallsworth K, Plötz T, et al. Physical activity, sedentary behaviour and metabolic control following stroke: a cross-sectional and longitudinal study. PLoS One 2013;8:e55263.

62 Royston P, Altman DG. Regression using fractional polynomials of continuous covariates: parsimonious parametric modelling. Journal of the Royal Statistical Society: Series C 1994;43:429-53.

63 Hadley Wickham RF, Henry L, Muller K. dplyr: a grammar of data manipulation. Available: https://CRAN.R-project.org/package=dplyr

64 Nicholas Tierney DC, McBain M, Fay C, et al. naniar: data structures, summaries, and Visualisations for missing data. Available: https:// cran.r-project.org/web/packages/naniar/index.html 
65 Gareth Ambler AB. Package 'mfp'; 2015.

66 Wallis JA, Webster KE, Levinger $\mathrm{P}$, et al. What proportion of people with hip and knee osteoarthritis meet physical activity guidelines? A systematic review and meta-analysis. Osteoarthritis Cartilage 2013;21:1648-59.

67 Aadahl M, Kjaer M, Jørgensen T. Associations between overall physical activity level and cardiovascular risk factors in an adult population. Eur J Epidemiol 2007;22:369-78.

68 Schaller N, Seiler H, Himmerich S, et al. Estimated physical activity in Bavaria, Germany, and its implications for obesity risk: results from the BVS-II study. Int J Behav Nutr Phys Act 2005;2.

69 Norman A, Bellocco R, Bergström A, et al. Validity and reproducibility of self-reported total physical activity-differences by relative weight. Int J Obes 2001;25:682-8.

70 Holden MA, Nicholls EE, Young J, et al. Exercise and physical activity in older adults with knee pain: a mixed methods study. Rheumatology 2015;54:413-23.

71 Teixeira PJ, Carraça EV, Markland D, et al. Exercise, physical activity, and self-determination theory: a systematic review. International Journal of Behavioral Nutrition and Physical Activity 2012;9.

72 Hammond LE, Lilley JM, Pope GD, et al. 'We've just learnt to put up with it': an exploration of attitudes and decision-making surrounding playing with injury in English professional football. Qual Res Sport Exerc Health 2014;6:161-81.

73 Roderick M, Waddington I, Parker G. Playing hurt: managing injuries in English professional football. International review for the sociology of sport 2000;35:165-80.

74 Meggs J, Ditzfeld C, Golby J. Self-concept organisation and mental toughness in sport. J Sports Sci 2014;32:101-9.

75 Nicholls AR, Polman RCJ, Levy AR, et al. Mental toughness, optimism, pessimism, and coping among athletes. Pers Individ Dif 2008;44:1182-92.

76 Filbay S, Pandya T, Thomas B, et al. Quality of life and life satisfaction in former athletes: a systematic review and metaanalysis. Sports Med 2019;49:1723-38.

77 Kobayashi S, Pappas E, Fransen M, et al. The prevalence of patellofemoral osteoarthritis: a systematic review and meta-analysis. Osteoarthritis and Cartilage 2016;24:1697-707.

78 Harvey SB, Øverland S, Hatch SL, et al. Exercise and the prevention of depression: results of the HUNT cohort study. Am J Psychiatry 2018:175:28-36.

79 Salmon P. Effects of physical exercise on anxiety, depression, and sensitivity to stress: a unifying theory. Clin Psychol Rev 2001;21:33-61.

80 Vasiliadis H-M, Bélanger MF. The prospective and concurrent effect of exercise on health related quality of life in older adults over a 3 year period. Health Qual Life Outcomes 2018;16:15.

81 Bäckmand H, Kaprio J, Kujala U, et al. Influence of physical activity on depression and anxiety of former elite athletes. Int J Sports Med 2003;24:609-19.
82 Hays RD, Morales LS. The RAND-36 measure of health-related quality of life. Ann Med 2001;33:350-7.

83 Simon JE, Docherty CL. Current health-related quality of life in former national collegiate athletic association division I collision athletes compared with contact and Limited-Contact athletes. J Athl Train 2016;51:205-12.

84 Simon JE, Docherty CL. Current health-related quality of life is lower in former division I collegiate athletes than in non-collegiate athletes. Am J Sports Med 2014;42:423-9.

85 Sorenson SC, Romano R, Scholefield RM, et al. Holistic life-span health outcomes among elite intercollegiate student-athletes. J Athl Train 2014;49:684-95.

86 Gouttebarge V, Aoki H, Kerkhoffs GMMJ. Lower extremity osteoarthritis is associated with lower health-related quality of life among retired professional footballers. Phys Sportsmed 2018;46:471-6

87 Cameron KL, Thompson BS, Peck KY, et al. Normative values for the KOOS and WOMAC in a young athletic population: history of knee ligament injury is associated with lower scores. Am J Sports Med 2013;41:582-9.

88 McAllister DR, Motamedi AR, Hame SL, et al. Quality of life assessment in elite collegiate athletes. Am J Sports Med 2001:29:806-10.

89 Valovich McLeod TC, Decoster LC, Loud KJ, et al. National athletic trainers' association position statement: prevention of pediatric overuse injuries. J Athl Train 2011;46:206-20.

90 Gardner AW, Montgomery PS, Wang M, et al. Predictors of healthrelated quality of life in patients with symptomatic peripheral artery disease. J Vasc Surg 2018;68:1126-34.

91 Zhao Y, Chung P-K. Neighborhood environment walkability and health-related quality of life among older adults in Hong Kong. Arch Gerontol Geriatr 2017;73:182-6.

92 Ninković S, Avramov S, Harhaji V, et al. Influence of different levels of sports activities on the quality of life after the reconstruction of anterior cruciate ligament. Med Pregl 2015;68:116-21.

93 Royston P, Sauerbrei W. Building multivariable regression models with continuous covariates in clinical epidemiology-with an emphasis on fractional polynomials. Methods Inf Med 2005;44:561-71.

94 Brenner PS, DeLamater JD. Social desirability bias in self-reports of physical activity: is an exercise identity the culprit? Soc Indic Res 2014;117:489-504.

95 Crutzen R, Göritz AS. Does social desirability compromise selfreports of physical activity in web-based research? Int J Behav Nutr Phys Act 2011;8.

96 Sesso R, Rodrigues-Neto JF, Ferraz MB. Impact of socioeconomic status on the quality of life of ESRD patients. Am J Kidney Dis 2003:41:186-95.

97 Penson DF, Stoddard ML, Pasta DJ, et al. The association between socioeconomic status, health insurance coverage, and quality of life in men with prostate cancer. J Clin Epidemiol 2001;54:350-8. 